\title{
Strength and fracture of uranium, plutonium and several their alloys under shock wave loading
}

\author{
V.K. Golubev \\ Russian Federal Nuclear Center - VNIIEF, Sarov, Russia
}

\begin{abstract}
Results on studying the spall fracture of uranium, plutonium and several their alloys under shock wave loading are presented in the paper. The problems of influence of initial temperature in a range of $-196-800^{\circ} \mathrm{C}$ and loading time on the spall strength and failure character of uranium and two its alloys with molybdenum and both molybdenum and zirconium were studied. The results for plutonium and its alloy with gallium were obtained at a normal temperature and in a temperature range of $40-315^{\circ} \mathrm{C}$, respectively. The majority of tests were conducted with the samples in the form of disks $4 \mathrm{~mm}$ in thickness. They were loaded by the impact of aluminum plates $4 \mathrm{~mm}$ thick through a copper screen $12 \mathrm{~mm}$ thick serving as the cover or bottom part of a special container. The character of spall failure of materials and the damage degree of samples were observed on the longitudinal metallographic sections of recovered samples. For a concrete test temperature, the impact velocity was sequentially changed and therefore the loading conditions corresponding to the consecutive transition from microdamage nucleation up to complete macroscopic spall fracture were determined. The conditions of shock wave loading were calculated using an elasticplastic computer program. The comparison of obtained results with the data of other researchers on the spall fracture of examined materials was conducted.
\end{abstract}

\section{Introduction}

Studying spall fracture of the samples of uranium and its alloys under shock loading was carried out by various researchers [1-13]. In work [1] the samples of uranium $1.5-6 \mathrm{~mm}$ in thickness were loaded by uranium projectiles $0.8-3 \mathrm{~mm}$ thick speeded up to velocities of $73-175 \mathrm{~m} / \mathrm{s}$. Recording the free surface velocity of samples was made by means of a capacitive gauge. On the basis of such recording the value of $2.4 \mathrm{GPa}$ was obtained for the spall strength of uranium and the measure of sample spall failure was offered. In work [2] the samples of uranium $7.5 \mathrm{~mm}$ in thickness were loaded by sapphire projectiles $6.3 \mathrm{~mm}$ thick speeded up to velocities of 129-426 m/s. Recording the free surface velocity of samples was made by means of a laser interferometer. Increasing the spall strengths of uranium from 2.7 to $3.3 \mathrm{GPa}$ was noted with the growth of shock wave loading intensity. In work [3] the samples of uranium of $7 \mathrm{~mm}$ in thickness were loaded by sapphire projectiles $8 \mathrm{~mm}$ thick. Increasing the spall strengths of uranium from 1.7 to $2.6 \mathrm{GPa}$ was noted with the growth of a free surface velocity from 60 to $500 \mathrm{~m} / \mathrm{s}$. The alloys of uranium with titanium, molybdenum, rhodium and niobium were also studied in this work. If at a free surface velocity of about $100 \mathrm{~m} / \mathrm{s}$ the values of the spall strength of alloys were in a range of 2.5-3.2 GPa, then at a free surface velocity of about $500 \mathrm{~m} / \mathrm{s}$ this range was about 3.2-3.5 GPa.

In works [4-6] the results on studying spall fracture of the uranium samples of two grades of carbon impurity content were given. The samples $4-5 \mathrm{~mm}$ in thickness were loaded by quartz projectiles $4 \mathrm{~mm}$ thick speeded up to velocities of $2700-600 \mathrm{~m} / \mathrm{s}$. Metallographic examination of recovered samples was made. It was not noted an obvious influence of material purity on the spall strength of uranium, which was in a range of $1.5-1.9 \mathrm{GPa}$. The complete spall fracture of samples occurred in the range of loading stresses from 3.5 to $5.3 \mathrm{GPa}$. In work [7] spall fracture of an alloy of uranium with titanium was studied. Results on the spall strengths of the alloy and on its character of spall failure were obtained. In works $[8,9]$ the results of studying spall fracture of an alloy of uranium with niobium were given. The spall strength value of $2.6 \mathrm{GPa}$ was obtained for the alloy and the complete spall fracture of samples occurred in the range of loading stresses from 4.3 to $5.5 \mathrm{GPa}$.

In work [10] the samples of uranium $0.1 \mathrm{~mm}$ in thickness were loaded by copper projectiles $0.05 \mathrm{~mm}$ thick in the range of shock wave compression from 1.6 to $10.5 \mathrm{GPa}$. The values of 4.4 and $2.9 \mathrm{GPa}$ were obtained for the spall strength of high-purity and unpurified rolling uranium. In work [11] the samples of an alloy of uranium with titanium $6 \mathrm{~mm}$ in thickness were loaded by projectiles $2 \mathrm{~mm}$ thick speeded up to velocities of $130-500 \mathrm{~m} / \mathrm{s}$. Increasing the spall strengths of an alloy from 2.3 to $4.1 \mathrm{GPa}$ was noted with the growth of shock wave loading intensity. In work [12] spall fracture of uranium and an alloy of uranium with titanium was studied in a temperature range of 20$860^{\circ} \mathrm{C}$. The samples $2 \mathrm{~mm}$ in thickness were loaded by copper projectiles $1 \mathrm{~mm}$ thick speeded up to a velocity of $300 \mathrm{~m} / \mathrm{s}$. The velocity of the free surface of samples was measured using a laser interferometer. Increasing the spall strengths of uranium was noted in the temperature range corresponding to the existence of the $\beta$-phase of uranium.

As to spall fracture of plutonium, the work [13] can be noted in which the explosive compression of a sphere made of an alloy of plutonium with gallium was studied. As a result of wave interactions, the two concentric spall cracks were formed in the sphere after loading. Not only voids but also microcracks were observed in the structure of spallation zones that enabled authors to make a supposition on the phase state of the alloy at a moment of spall cracks formation. An analogous work on the explosive 
compression of a sphere made of pure plutonium was reported by authors at the conference [14].

In this paper the results of studying the spall fracture of uranium, plutonium and several their alloys under shock loading are considered. The results were obtained and partly presented in a number of works [15-22]. Studying spall fracture of these materials was also conducted under other loading conditions, in particular under the action of intensive radiation fluxes [23,24] and the explosion of massive [24] and sheet [25] charges of high explosive. However, these results are mentioned only for comparison.

\section{Materials and procedures}

The results obtained for such metals and alloys as uranium, an alloy of uranium with 1.4 mass \% of molybdenum (UM), a double alloy of uranium with 1.4 mass \% of molybdenum and 0.7 mass \% of zirconium (UMZ), plutonium and an alloy of plutonium with 1.6 mass $\%$ of gallium (PG) are presented in the paper. The samples of uranium were made of a material in three various initial states: a rod in a delivery state, a rod after low-temperature annealing and a plate in a delivery state. Other samples were made of materials in a delivery state. The samples of materials in the form of dicks $4 \mathrm{~mm}$ in thickness and 30 or $40 \mathrm{~mm}$ in diameter were fastened to a copper screen $12 \mathrm{~mm}$ thick serving by the cover or the bottom part of a hermetic container. The heating of the samples to a necessary temperature $T$ in a range up to $800{ }^{\circ} \mathrm{C}$ was carried out together with the container by means of an electric heater. The cooling of the samples to a temperature of $-196{ }^{\circ} \mathrm{C}$ was performed by a rather long holding in a vessel with liquid nitrogen. Shock wave loading of samples was carried out by the impact of an aluminum plate $4 \mathrm{~mm}$ thick on the screen. Speeding up the aluminum plate to a necessary velocity $w$ was executed by the explosion of a sheet explosive charge.

Studying the influence of loading time on spall fracture was conducted too. The samples of uranium $6 \mathrm{~mm}$ in thickness were loaded by the impact of aluminum plate $4 \mathrm{~mm}$ thick. The thinner samples $1.5 \mathrm{~mm}$ in thickness were loaded by the impact of aluminum plate $0.9 \mathrm{~mm}$ thick. Such tests were conducted for both uranium and alloys samples.

After testing the samples were bisected and their longitudinal sections underwent electrolytic polishing and etching. Observing the degree and character of samples spall fracture was performed by means of optical and metallographic microscopes at a magnification up to 1000 times. The degree and character of spall fracture of all samples tested at various temperatures and levels of loading pressure were revealed. The degree of failure was conventionally subdivided into a number of gradations, from complete spall fracture to the presence of a small amount of isolated microdamages in the section of a sample and further to the absence of microdamages in a section at a magnification up to 1000 times.

The conditions of shock wave loading of samples were determined with the use of a program for the numerical computation of one-dimensional elastic-plastic flows [26].

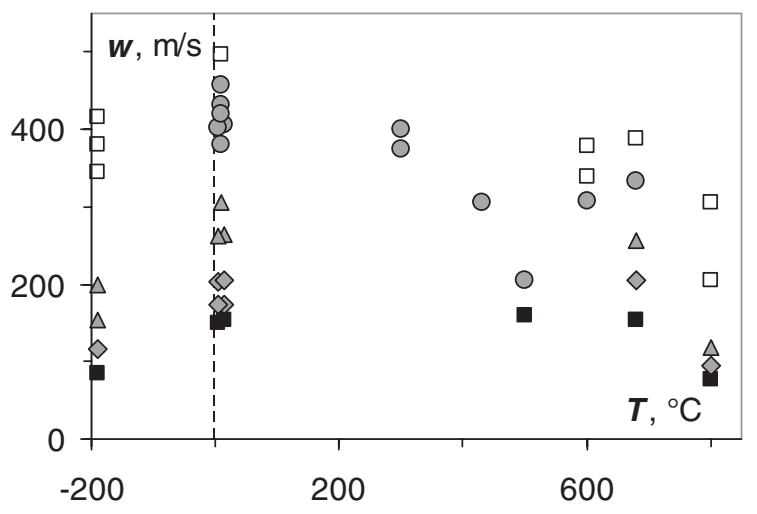

Fig. 1. The influence of temperature and impact velocity on the degree of spall failure of uranium samples.

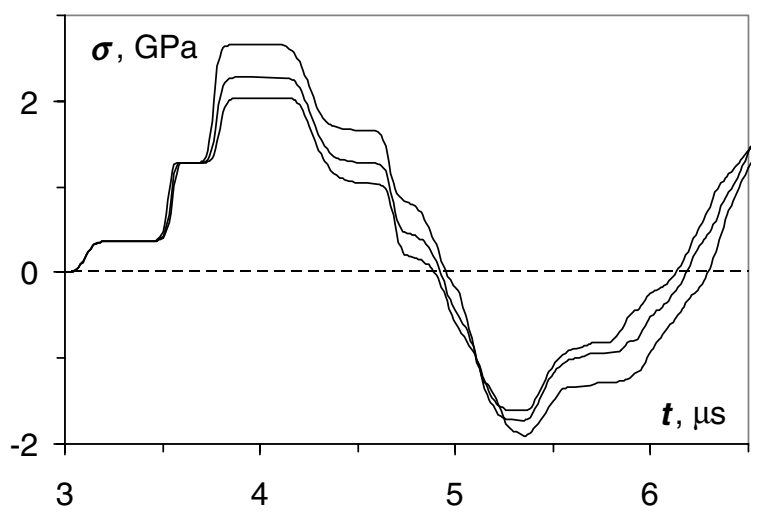

Fig. 2. Stress change in the middle transversal section of uranium samples at impact velocities of 154,173 and $203 \mathrm{~m} / \mathrm{s}$.

The parameters of the Me-Gruneisen equation of state were fitted on the basis of shock wave compression data for a low pressure region [27]. The elastic-plastic properties of the plate-impactor, screen and samples materials were used in calculations. The initial phase state of uranium (being at $\alpha$-, $\beta$-or $\gamma$-phase) and the $\delta$ - $\alpha$ - and $\delta$ - $\gamma$-transitions occurring in PG alloy during shock wave loading were taken into account.

\section{Obtained results}

Some results on the influence of temperature on spall fracture of uranium $[14,15,18]$ are presented in Figs. 1-4. In the captions, $b$ is the breadth of a structure fragment. In Fig. 1 the light and dark squares correspond to the complete spall fracture of samples and the retention of microscopic integrity of uranium, and the darkened markers characterize intermediate failure gradations. The calculated profiles of a longitudinal stress shown in Fig. 2 for three impact velocities make it possible to determine the spall strength $\sigma_{\mathrm{s}}$ of uranium at a normal temperature and a realizable strain rate $\varepsilon$. Here the spall strength $\sigma_{\mathrm{s}}=$ $1.7 \mathrm{GPa}$ corresponds to the strain rate $=4 \cdot 10^{5} 1 / \mathrm{s}$.

At a temperature of $-196^{\circ} \mathrm{C}$ an intensive twinning is observed in all the volume of a sample. Spall fracture has a brittle nature at this temperature. The nucleation and 


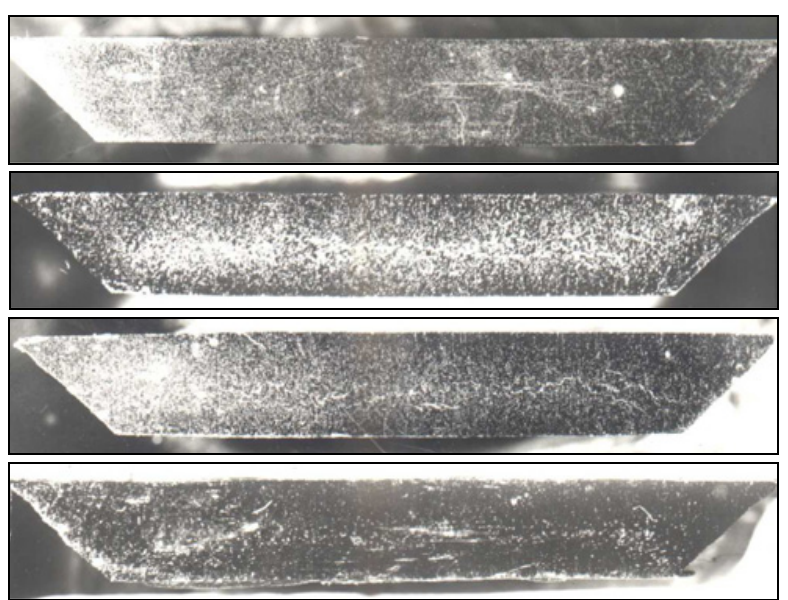

Fig. 3. The sections of uranium samples tested at different temperatures, from top to bottom: $T=-196^{\circ} \mathrm{C}, w=154 \mathrm{~m} / \mathrm{s}$; $T=430{ }^{\circ} \mathrm{C}, w=306 \mathrm{~m} / \mathrm{s} ; T=680^{\circ} \mathrm{C}, w=334 \mathrm{~m} / \mathrm{s}$; $T=800^{\circ} \mathrm{C}, w=118 \mathrm{~m} / \mathrm{s}$.

growth of microcracks occurs preferentially along twins. At a normal temperature the nucleation of microcracks occurs commonly at carbonitride inclusions. The nucleation of microcracks along twins and intergranular cracking are observed at this temperature too. The further development of fracture is associated with the formation and growth of cavities in the places of multiple cracking. At a temperature of $300^{\circ} \mathrm{C}$ the process of failure has a mainly ductile nature and is connected with the formation and growth of arbitrary shape voids. At a temperatures of 430 and $500{ }^{\circ} \mathrm{C}$ spall failure has an essentially ductile nature. The voids formed at carbonitride inclusions have a spherical shape and their growth and coalescence occur without any cracking of a material. At a temperature of $680^{\circ} \mathrm{C}$ uranium is in the $\beta$-phase, and the nucleation and growth of microcracks occurs in this case along the boundaries of grains and subgrains. The further development of fracture is associated with the formation and growth of cavities in the places of multiple cracking of a material. At a temperature of $800^{\circ} \mathrm{C}$ uranium is in the $\gamma$-phase and the character of its failure becomes again essentially ductile, related to the formation of spherical voids, their growth and subsequent coalescence.

It is necessary to note the specific character of spall fracture of uranium samples at a temperature of $600^{\circ} \mathrm{C}$. In this case the ritting of small fragments or grains is observed but not the separation of a compact spall layer.

Some results on the influence of temperature on spall fracture of UM alloy $[14,16]$ are presented in Fig. 5-8. The calculated profiles of a longitudinal stress for three impact velocities are shown in Fig. 6. The spall stress value obtained for UM alloy at a normal temperature makes $2.6 \mathrm{GPa}$. Some results on the influence of temperature on spall fracture of UMZ alloy $[14,16]$ are presented in Fig. 9-12. The calculated profiles of a longitudinal stress for three impact velocities are shown in Fig. 10. The spall stress value obtained for UMZ alloy at a normal temperature makes $2.9 \mathrm{GPa}$.

Both the alloys are characterized by the martensitic structure in their initial state. The size of pseudograins was generally in the range of $100-200 \mu \mathrm{m}$ for UM alloy

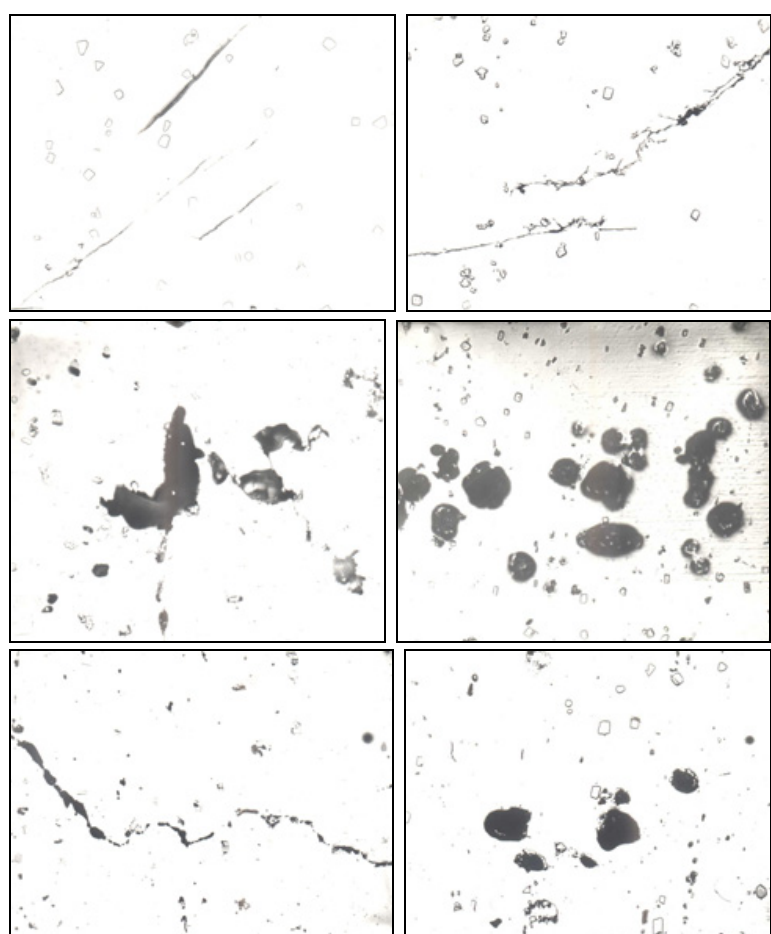

Fig. 4. The character of spall fracture of uranium at different temperatures, from left to right and from top to bottom: $T=$ $-196{ }^{\circ} \mathrm{C}, b=219 \mu \mathrm{m} ; T=0{ }^{\circ} \mathrm{C}, b=220 \mu \mathrm{m} ; T=300^{\circ} \mathrm{C}, b=$ $214 \mu \mathrm{m} ; T=430^{\circ} \mathrm{C}, b=582 \mu \mathrm{m} ; T=680^{\circ} \mathrm{C}, b=369 \mu \mathrm{m}$; $T=800^{\circ} \mathrm{C}, b=365 \mu \mathrm{m}$.

and of 200-1500 $\mu \mathrm{m}$ for UMZ alloy. The character of spall fracture is alike to a large degree for both the alloys. Spall fracture of alloys at a temperature of $-196^{\circ} \mathrm{C}$ has a brittle nature. Spall microdamages are thin and rather rectilinear microcracks. At a normal temperature the microcracks become more opened and less rectilinear. At a temperature of $400^{\circ} \mathrm{C}$ the fracture character of alloys becomes actually ductile. The spall damages look like ductile microcracks and cavities of arbitrary shape. At temperatures of 660$800{ }^{\circ} \mathrm{C}$ practically all formed microdamages are spherical voids. The nucleation of spall microdamages under the low levels of tensile stresses and all temperatures occurs substantially at the carbonitride inclusions. Increase of the level of a tensile stress leads to such situation when the nucleation of microdamages begins to occur virtually in any place.

The quantitative metallographic examination of a spall failure degree was carried out for several tested samples [17]. The sizes of observed spall damages, their quantity and distribution through the thickness of a sample were determined in the central zones of sample sections. For example, 6, 44 and 506 microcracks of sizes 0.01$0.49 \mathrm{~mm}$ were observed in the sections of uranium samples loaded at velocities of 173, 206 and $262 \mathrm{~m} / \mathrm{s}$ at a normal temperature. Studying the influence of loading time on spall fracture of uranium and its alloys was conducted too. The spall strength value of $1.8 \mathrm{GPa}$ was obtained when the samples of uranium $6 \mathrm{~mm}$ in thickness were loaded by the aluminum plates $4 \mathrm{~mm}$ thick. In the case of using the uranium sample $1.5 \mathrm{~mm}$ in thickness and the aluminum 


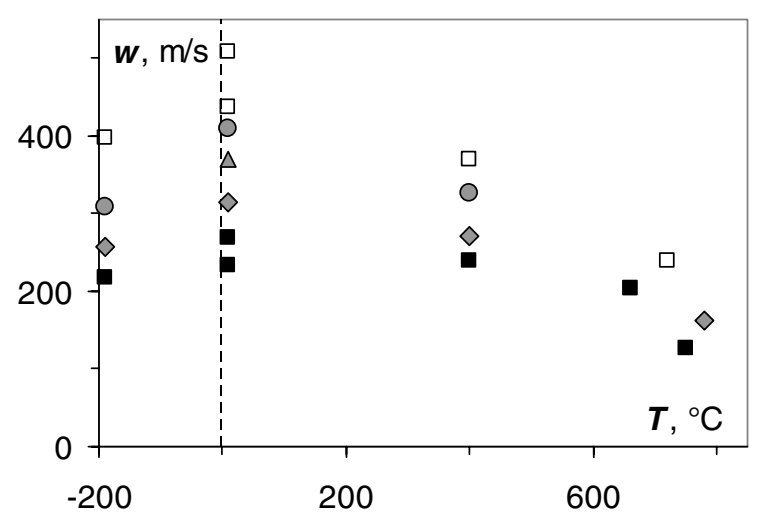

Fig. 5. The iInfluence of temperature and impact velocity on the degree of spall failure of UM alloy samples.

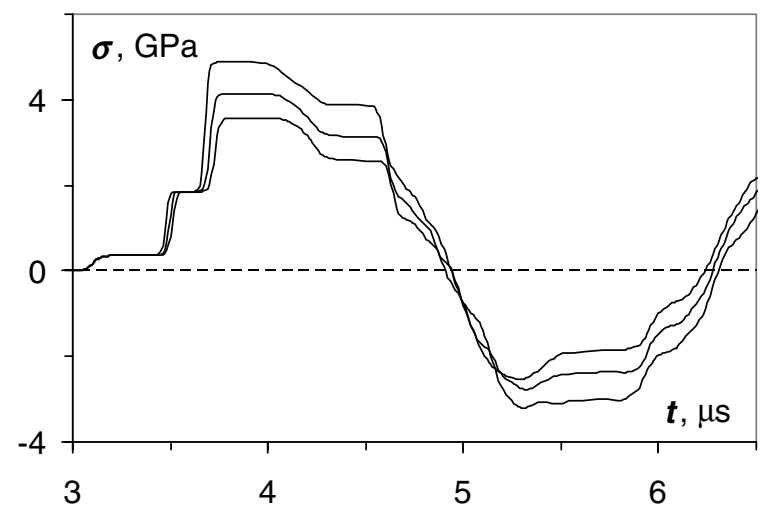

Fig. 6. Stress change in the middle transversal section of UM alloy samples at impact velocities of 270, 314 and $370 \mathrm{~m} / \mathrm{s}$.

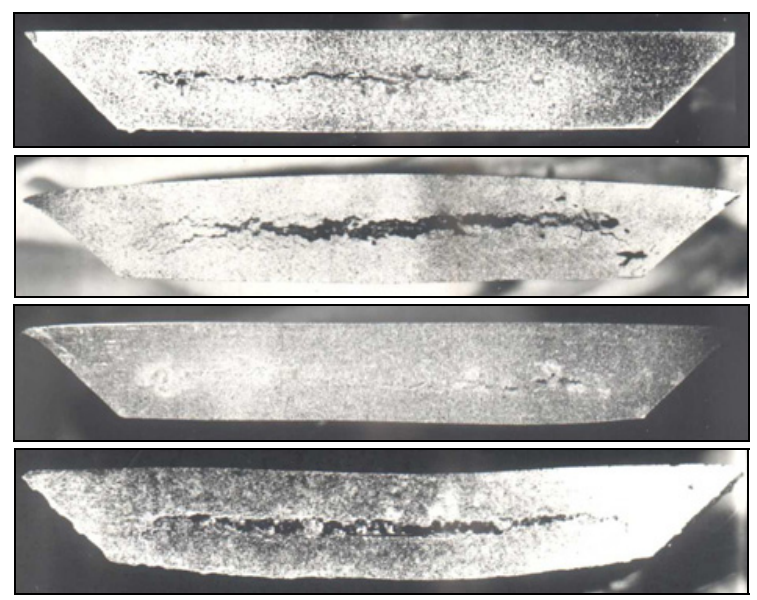

Fig. 7. The sections of UM alloy samples tested at different temperatures, from top to bottom: $T=-196^{\circ} \mathrm{C}, w=308 \mathrm{~m} / \mathrm{s}$; $T=0{ }^{\circ} \mathrm{C}, w=438 \mathrm{~m} / \mathrm{s} ; T=400^{\circ} \mathrm{C}, w=373 \mathrm{~m} / \mathrm{s} ; T=720^{\circ} \mathrm{C}$, $w=239 \mathrm{~m} / \mathrm{s}$.

plate-impactor $0.9 \mathrm{~mm}$ thick, the spall strength value of 2.1 GPa was obtained. Analogous tendencies were also observed for uranium alloys.

Some results on spall fracture of plutonium and PG alloy [20-22] are presented in Fig. 13-16. The conditions of macroscopic spall fracture were determined and the metallographic examination of samples was performed later. The profiles of a longitudinal stress shown in Fig. 14

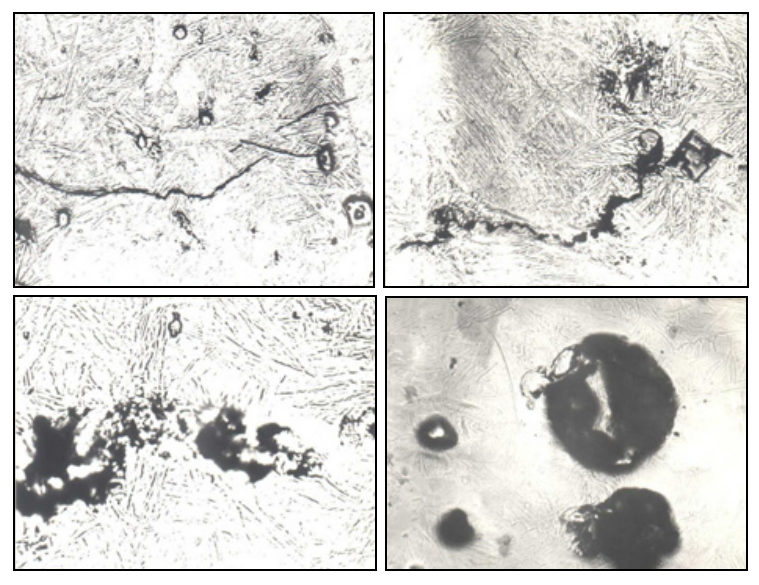

Fig. 8. The character of spall fracture of UM alloy at different temperatures, from left to right and from top to bottom: $T=$ $-196{ }^{\circ} \mathrm{C}, b=160 \mu \mathrm{m} ; T=0{ }^{\circ} \mathrm{C}, b=133 \mu \mathrm{m} ; T=400^{\circ} \mathrm{C}$, $b=133 \mu \mathrm{m} ; T=770^{\circ} \mathrm{C}, b=160 \mu \mathrm{m}$.

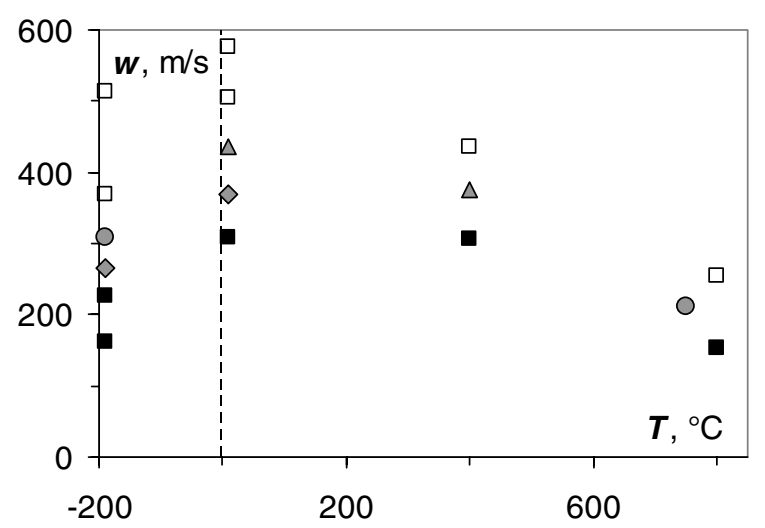

Fig. 9. The influence of temperature and impact velocity on the degree of spall failure of UMZ alloy samples.

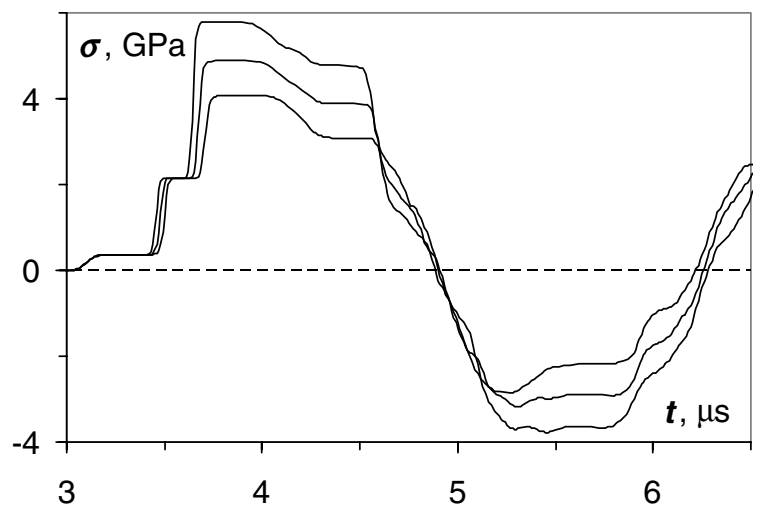

Fig. 10. Stress change in the middle transversal section of UMZ alloy samples at impact velocities of 308, 370 and $437 \mathrm{~m} / \mathrm{s}$.

correspond to the loading conditions of plutonium and PG alloy preceding the complete spall fracture. The calculated value of a critical tensile stress makes in this case about $1.25 \mathrm{GPa}$ for both the materials.

\section{Discussion and conclusions}

The part of obtained results on spall fracture of uranium, plutonium and their alloys under shock wave loading 


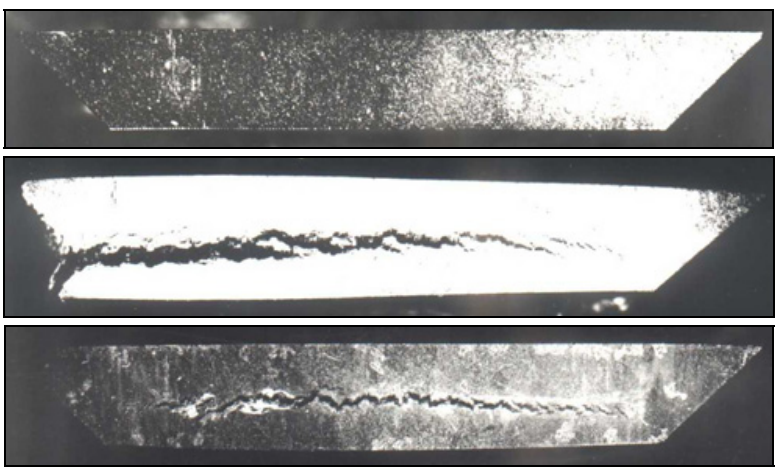

Fig. 11. The sections of UMZ alloy samples tested at different temperatures, from top to bottom: $T=0{ }^{\circ} \mathrm{C}, w=370$ and $576 \mathrm{~m} / \mathrm{s} ; T=400^{\circ} \mathrm{C}, w=437 \mathrm{~m} / \mathrm{s}$.

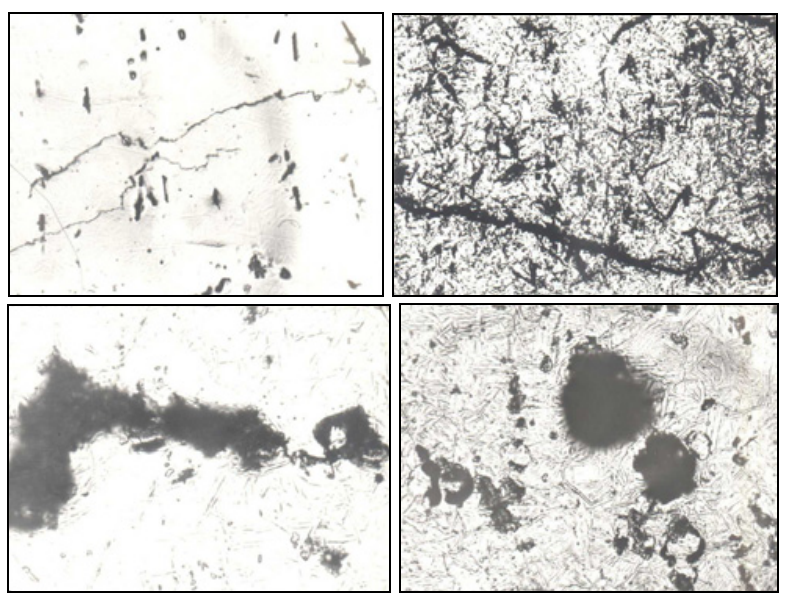

Fig. 12. The character of spall fracture of UMZ alloy at different temperatures, from left to right and from top to bottom: $T=$ $-196{ }^{\circ} \mathrm{C}, b=160 \mu \mathrm{m} ; T=0{ }^{\circ} \mathrm{C}, b=267 \mu \mathrm{m} ; T=400^{\circ} \mathrm{C}$, $b=100 \mu \mathrm{m} ; T=800^{\circ} \mathrm{C}, b=160 \mu \mathrm{m}$.

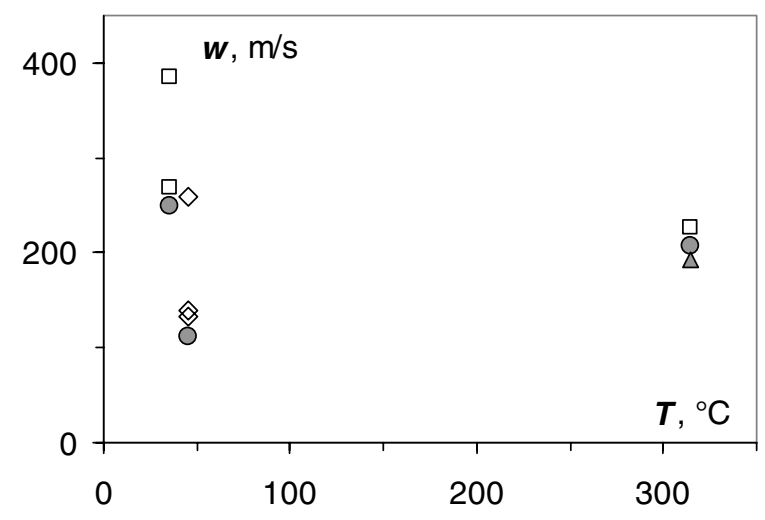

Fig. 13. The influence of impact velocity and temperature on the degree of spall failure of plutonium and PG alloy samples.

has been presented in the paper. It has been shown that the temperature of testing influences appreciably on the conditions of spall fracture of uranium and its alloys and on the character of their fracture. The character of uranium fracture is especially interesting at a temperature of $600{ }^{\circ} \mathrm{C}$. It is necessary to note that the polymorphic $\alpha$ - $\beta$-transition and arising of spall fracture are occurred at the same tensile stresses in this case. The comparison of obtained results with the results of studying the fracture character

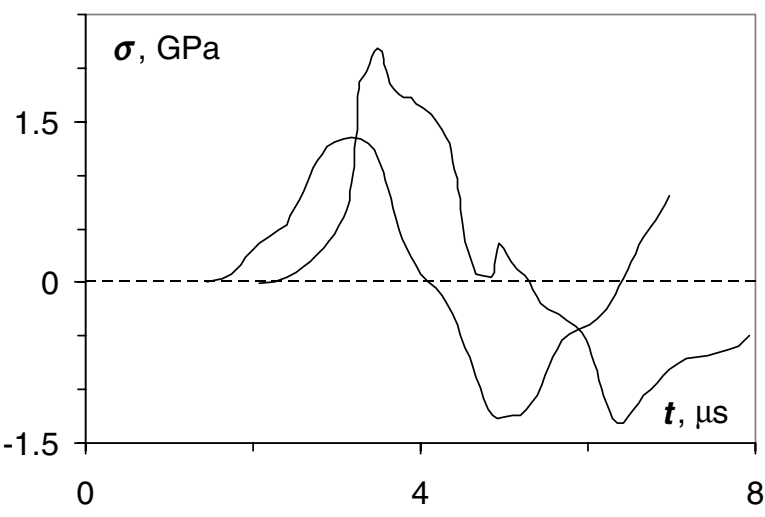

Fig. 14. Stress change in the transversal sections of a plutonium sample on a coordinate $x=2.3 \mathrm{~mm}$ at an impact velocity of $113 \mathrm{~m} / \mathrm{s}$ and a PG alloy sample on a coordinate $x=2.7 \mathrm{~mm}$ at an impact velocity of $257 \mathrm{~m} / \mathrm{s}$.
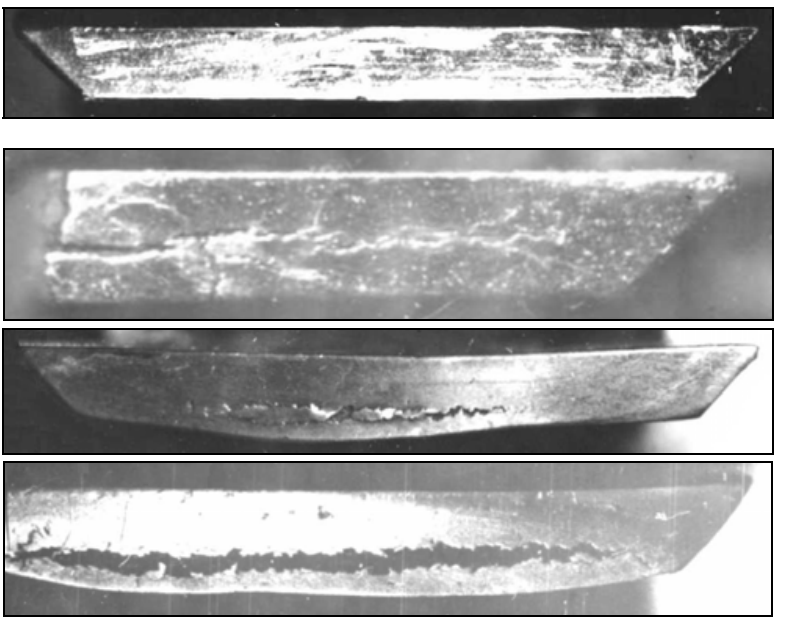

Fig. 15. The sections, from top to bottom, of plutonium samples, $w=113 \mu 134 \mathrm{~m} / \mathrm{s}$, and PG alloy samples: $T=40^{\circ} \mathrm{C}, w=$ $262 \mathrm{~m} / \mathrm{s} ; T=315^{\circ} \mathrm{C}, w=226 \mathrm{~m} / \mathrm{s}$.
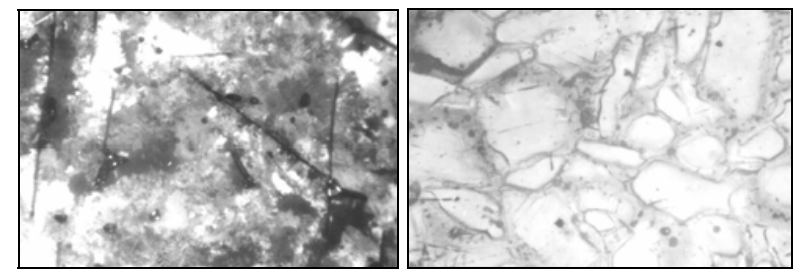

Fig. 16. The character of spall fracture nucleation in plutonium (left) and PG alloy (right), $b=244 \mu \mathrm{m}$.

of uranium in the static conditions of uniaxial tension [28] indicates that the mechanisms of uranium fracture under shock wave and static tension are similar. The results on spall fracture of plutonium have been obtained and the influence of temperature on the conditions of spall fracture of PG alloy has been noted. It has been shown that the loading time also influences essentially on the conditions of spall fracture of uranium and its alloys.

The comparison of the results obtained for uranium and its alloys with the data of other researchers obtained in the close conditions of shock loading and cited shortly in the introduction points at their good agreement on the values of the spall strength, the conditions of complete fracture and the character of spall failure. The results 
on the influence of temperature on the spall strength of uranium [12] obtained using the modern interferometric method of recording have the special importance in this regard. They confirm to a large degree the significance of the results of studying the spall fracture of uranium in three phase states obtained using simple experimental procedures [15].

It can be noted that the obtained results on spall fracture of uranium and its alloys under shock loading agree rather acceptably with the results obtained for the wedge samples of the same materials loaded by the sheet charges of plastic explosives [25]. In this case the starting places of spall cracks were determined in tested samples and the tensile stresses were estimated in these places. Spall fracture of uranium was also studied at the fast heating of samples by high-intensity pulses of penetrating radiation $[23,24]$. The heating temperatures of the samples $5-10 \mathrm{~mm}$ in thickness were in a range from 160 to $800^{\circ} \mathrm{C}$ and the characteristic time of loading was about $2 \mu \mathrm{s}$. The character and degree of spall failure of uranium samples in all three phase states and the correspondent calculated tensile stresses were in good keeping with the results obtained under shock loading. Thus it can be concluded that the numerous result obtained to the present time on determination of the conditions of spall fracture of uranium and its alloys in the conditions of shock loading can be used for prediction of the behavior of samples of these materials in the conditions of relatively low-intensity explosive loading and in the conditions of fast heating by high-intensity pulses of penetrating radiation.

\section{References}

1. S. Cochran, D. Banner, J. Appl. Phys. 48(7), 2729 (1977)

2. D.E. Grady, Metallurgical Applications of ShockWave and High-Strain-Rate Phenomena 763 (Marcel Dekker Inc., New York, 1986)

3. J. Buchar, S. Rolc, J. Pechacek, J. Krejci, Journal de Physique IV. Colloque C3 1, 197 (1991)

4. R.S. Hixson, J.E. Vorthman, R.L. Gustavsen et al., Shock Compression of Condensed Matter - 1997239 (AIP, New York, 1998)

5. A.K. Zurek, J.D. Embury, A. Kelly et al., Shock Compression of Condensed Matter - 1997423 (AIP, New York, 1998)

6. D.L. Tonks, R. Hixson, R.L.Gustavsen et al., Shock Compression of Condensed Matter - 1997239 (AIP, New York, 1998)

7. A.K. Zurek, J. Nucl. Mater. 264(1-2), 155 (1999)

8. R.S. Hixson, J.E. Vorthman, A.K. Zurek et al., Shock Compression of Condensed Matter - 1999489 (AIP, New York, 2000)
9. D.L. Tonks, J.E. Vorthman, R. Hixson et al., Shock Compression of Condensed Matter - 1999329 (AIP, New York, 2000)

10. D.L. Robbins, A.M. Kelly, D.J. et al., Shock Compression of Condensed Matter - 2001499 (AIP, New York, 2002)

11. B. Herrmann, A. Landau, D. Shvarts et al., Shock Compression of Condensed Matter - 20011306 (AIP, New York, 2000)

12. E. Zaretsky, B. Herrmann, D. Shvarts, Shock Compression of Condensed Matter - 2005292 (AIP, New York, 2006)

13. E.A. Kozlov, B.V. Litvinov, L.F. Timofeeva, Physics of Metals and Metallurgy (rus) 81(6), 139 (1996)

14. E.A. Kozlov, L.F. Timofeva, Program Int. Conf. "Plutonium Futures - The Science 2010" (Keysyone, Colorado, USA, 2010) http: //wwW . new . ans.org/ meetings/m_92

15. V.K. Golubev, S.A. Novikov, Yu.S. Sobolev, N.A. Yukina, VANT: Materials Science and New Materials 2, 8 (1989).

16. V.K. Golubev, Yu.S. Sobolev, N.A. Yukina, Metals (rus) 2, 123 (1997)

17. V.K. Golubev, Yu.S. Sobolev, N.A. Yukina, Metals (rus) 1, 107 (1998)

18. V.K. Golubev, Proc. IV Sci. Conf. Volga Reg. RARAN Center "Modern Methods of Design and Adjustment of Rocket and Artillery Armaments" 693 (RFNCVNIIEF, Sarov, 2006)

19. V.K. Golubev, Abstr. Int. Conf. "Shock Waves in Condensed Matter" 241 (Novgorod, 2010)

20. Yu.V. Bat'kov, V.K. Golubev, S.A. Novikov et al., VANT. Impulse Reactors and Simple Critical Assemblies (rus) 1, 40 (1991)

21. V.K. Golubev, Yu.S. Sobolev, I.R. Trunin, Problems of Strength (rus) 5, 100 (1998)

22. V.K. Golubev, Yu.S. Sobolev, I.R. Trunin, Appl. Mech. Tech. Phys. (rus) 39(4), 135 (1998)

23. V.K. Golubev, L.P. Karpich, S.A. Novikov et al., VANT. Impulse Reactors and Simple Critical Assemblies (rus) 1, 37 (1991)

24. V.K. Golubev, Abstr Int Conf. "V Zababakhin Scientific Talks” 151 (RFNC-VNIITF, Snezhinsk, 1998)

25. V.K. Golubev, Yu.S. Sobolev, N.A. Yukina, Physics and Chemistry of Materials Processing (rus) 6, 50 (1997)

26. N.F. Gavrilov, G.G. Ivanova, Selin V.N., Sofronov V.N., VANT. Methods and Programs of Numerical Solution of Problems of Mathematical Physics 3, 11 (1982)

27. V.K. Golubev, Abstr XXI Int Conf. "Equations of State of Matter" 22 (Elbrus, 2006)

28. A.L.W. Collins, D.M.R. Taplin, J. Materials Sci. 13(10), 2249 (1978) 